\title{
EL TEATRO Y LOS MEDIOS AUDIOVISUALES: LA SITUACIÓN DE LOS ESTUDIOS EN ESPAÑA
}

\author{
Simone TRECCA \\ Università degli Studi Roma Tre \\ strecca@uniroma3.it
}

Resumen: La variedad de los fenómenos que atañen a las relaciones entre el teatro y los medios audiovisuales, en lo que concierne tanto los aspectos pragmáticos y receptivos como los rasgos textuales, expresivos y comunicativos, produce un diálogo continuo que no deja de surtir sus efectos en el desarrollo de los medios y de la crítica. En el presente trabajo se intenta dar cuenta de la reciente evolución de tales estudios en España.

Abstract: The wide range of phenomena concerning the relationships between theatre and audiovisual media, with regard to pragmatic and reception matters, as well as textual, expressive and communicative aspects, produces an ongoing dialogue which is bringing about important results in the development of both media and criticism. In this study a review on the recent evolution of these studies in Spain is outlined.

Palabras clave: Teatro. Medios Audiovisuales. Escena. Imagen. Crítica española. 
Key Words: Theatre. Audiovisual media. Stage. Image. Spanish Criticism.

\section{MÁS ALLÁ DE LA ADAPTACIÓN: EL PANORAMA CRÍTICO ESPAÑOL DE LAS ÚLTIMAS DÉCADAS}

El estudio de las relaciones entre el teatro y los medios audiovisuales se ha venido desarrollando, desde distintas perspectivas y con diferentes enfoques, durante las últimas décadas del siglo pasado y en los primeros años de este nuevo milenio. La investigación en tal ámbito, ante todo, tuvo que emanciparse de la preponderancia de los estudios sobre literatura y cine, en la mayoría de los cuales se tiene como objeto el texto literario y su relación con el relato fílmico, tanto a nivel de influencias mutuas como a nivel de intercambios entre ambos medios (adaptaciones, traducciones, transposiciones, intertextualiad, etc. $)^{1}$. En este marco se ha desarrollado especialmente una disciplina, la narratología comparada, que ya cuenta con numerosos seguidores en los países del mundo occidental, siendo España uno de los prolíficos en tal sentido, como ya señalara Peña-Ardid (2003), al constatar la ausencia y necesidad de un catálogo bibliográfico que recopilase dichos estudios, de cuya redacción ella misma se hacía cargo en aquella circunstancia.

Este campo de trabajo no excluyó, ni mucho menos, el análisis de la adaptación de textos teatrales a la pantalla, pero muy a menudo se acabó por tratar las producciones dramáticas de la misma manera que cualquier otro texto literario, sin tener en cuenta lo específico teatral, lo cual, lejos de ser ningún error de perspectiva - puesto que los estudios narratológicos mucho han aprovechado y siguen aprovechando a la investigación sobre el texto dramático-, sin embargo corre el riesgo de crear una jaula teórica demasiado angosta para el fenómeno que se quiere estudiar.

No es ninguna casualidad, a mi manera de ver, que uno de los terrenos de la investigación que antes y con mayor fuerza se ha independizado del en-

1 A partir del ya clásico libro de Urrutia (1984), hasta llegar a los de Peña Ardid (1992), Gutiérrez Carbajo (1993), Sánchez Noriega (2000), Pérez Bowie (2008). El problema de las relaciones textuales y expresivas entre literatura y cine, a parte de los abundantísimos ejemplos de análisis concretos de obras, también forma el objeto de trabajos teóricos y metodológicos menos extensos y, sin embargo, no menos rigurosos y relevantes: entre otros, Peña Ardid (1991 y 1996), sobre las influencias del cine en la novela; Fernández (2000), quien introduce su libro sobre Don Juan en el cine con unas consideraciones teóricas de gran interés; Paz Gago (2004), sobre la rentabilidad del método comparativo semiótico-textual. Véase además Pérez Bowie (2003 y 2004d), sobre las aportaciones más recientes en el estudio del fenómeno de la adaptación. 
foque fílmico-literario es justamente el más alejado de los problemas de tipo textual. Gracias a los sistemáticos trabajos de Utrera (1981, 1985, 1987), Ríos Carratalá (2002, 2003), Pérez Bowie (1996, 2004a) y García-Abad García (1997a, 1997b, 2005), entre otros ${ }^{2}$, contamos con rigurosas relaciones de la situación y recepción del cine en España y sobre las mutuas influencias con el teatro a lo largo de las distintas épocas, a partir de los comienzos del nuevo arte hasta el franquismo y parte del periodo democrático y actual. La trascendencia de este corte histórico y documental radica en la estrecha relación que teatro y cine siempre han tenido a nivel pragmático y receptivo, una relación más o menos conflictiva, según el momento, pero que presenta muchos motivos de reflexión a la hora de intentar estudiar el fenómeno a nivel teórico y analítico. Los cruces entre la historia del teatro y la historia del cine enseñan mucho, por comparación o contraste, sobre la estética de uno y otro sistema comunicativo y artístico, y sobre todo acerca de la percepción que de ambos han tenido autores, intelectuales, críticos y público.

Sirva como ejemplo, entre varios, de la fecundidad de este campo de estudios el trabajo de Pérez Bowie (2004a), compuesto por una recopilación de documentos comentados, pero que dan lugar a una serie de reflexiones, sistematizadas en la introducción, sobre el concepto de realismo en teatro y cine. Asimismo, es de notar, por el contrario, el hecho que también un trabajo con vocación marcadamente teórica, como es el de Guarinos (1996), no puede pasar por alto el dato histórico, tanto en lo referente a la práctica creativa y receptiva como a la crítica, acabando por dedicarle, y muy acertadamente, casi la mitad del volumen. Ni que decir tiene, que muchos de los trabajos de corte histórico-documental van salpicados de consideraciones y reflexiones más abstractas y generalizadoras sobre los dos medios, lo que supone un rico y continuo diálogo entre los varios aspectos de la cuestión.

Una situación semejante, me parece, se ha venido desarrollando en los últimos años respectivamente a los nexos que el teatro va estableciendo con los demás medios audiovisuales y con las nuevas tecnologías, unas relaciones no menos problemáticas $\mathrm{y}$, a veces, conflictivas, aunque en este campo mucho queda por hacer, a pesar de las significativas aportaciones recientes de algunos estudiosos ${ }^{3}$.

\footnotetext{
${ }^{2}$ Léanse también Dougherty (2001), Hueso (2001) y Vilches (2001).

3 Sobre la influencia de los medios audiovisuales y las nuevas tecnologías en la práctica escénica y la escritura teatral, léanse, entre otros: Sánchez (2002); Morales Astola (2003); Pérez Bowie (2006); Pérez Royo (2007); asimismo, acúdase a las Actas del XIII y del XV Seminarios Internacionales del Centro de Investigación de Semiótica Literaria, Teatral y Nuevas Tecnologías, Teatro, prensa y nuevas tecnolo-
} 
Es evidente que la situación que acabo de describir, si bien sumariamente, sumerge la cuestión de la adaptación fílmica de obras teatrales en una serie de consideraciones que problematizan el enfoque y los métodos para aproximarse a este fenómeno, el cual, por otra parte, no deja de llamar la atención de los estudiosos. Estados de la investigación sobre el tema en España se encuentran en Guarinos (1996 y 2003), Sánchez Noriega (1999 y 2000), Pulido Tirado (2002), Pérez Bowie (2003, 2004c y 2004d).

A continuación propongo una repartición de las cuestiones que acabo de esbozar en sendos apartados, en los que intentaré sintetizar posiciones y tendencias de la crítica y, en la medida de lo posible, indicar las líneas que dejan entrever los caminos que se ha venido emprendiendo hasta ahora.

\section{LAS «INFLUENCIAS» DEL CINE EN EL TEATRO}

La aparición del cine, en ello coinciden unánimemente los críticos, significó un choque estético y cultural sobre todo con el mundo del teatro, en su sentido más amplio, pues se impuso, el nuevo arte, como modelo de espectáculo y de diversión moderno y en rápida evolución en las formas y las técnicas. El antagonismo entre las dos maneras de entretenimiento, no obstante, deja de tener demasiada relevancia en sí, al considerar, como lo hace Pérez Bowie, que el teatro español, a la par que el europeo, ya se encontraba en una necesidad intrínseca de renovación y de salir de los esquemas rancios del naturalismo: «la irrupción del cine no fue el desencadenante de un proceso de transformación de la escena, sino un elemento más, sin duda importante pero no definitivo, que vino a avivarlo sumando argumentos a una polémica surgida a fines del siglo XIX en el seno de la reacción contra el canon naturalista» (Pérez Bowie, 2004a: 8). El impulso a la reteatralización de la escena y el consiguiente abandono de toda pretensión realista por parte del teatro

gías (Romera Castillo ed., 2004) y Tendencias estéticas al inicio del siglo XXI (Romera Castillo ed., 2006), respectivamente. Merecen especial referencia a este propósito los recientes y sistemáticos trabajos de Abuín González (2006 y 2008). Sobre las relaciones entre el teatro y la televisión, el libro de Guarinos (1992) sigue siendo el más sistemático trabajo escrito hasta ahora, aunque cabe sin duda señalar las contribuciones - con ocasión del XI Seminario Internacional del Centro de Investigación de Semiótica Literaria, Teatral y Nuevas Tecnologías, Del teatro al cine y la televisión en la segunda mitad del siglo XX (Romera Castillo ed., 2002) - de Espín (2002) sobre una posible metodología para el análisis semiótico de obras teatrales en la televisión y de Suárez (2002) acerca de la producción televisiva de teatro clásico, mientras que López Mozo (2002) dedicaba su atención a relatar la programación teatral en la televisión pública desde una perspectiva al mismo tiempo histórica y crítica. Asimismo, cabe indicar el interesante trabajo de Cornago Bernal (2002). 
son, en su momento, fenómenos que subyacen al estímulo del antinaturalismo y marcan, sin que pueda indicarse cuál sea la causa y cuál el efecto, una distancia ideológica entre el nuevo concepto finisecular de arte y el cine, considerado por algunos, en un principio, demasiado objetivo y documental para podérsele conceder el atributo de artístico. Así las cosas, es evidente que no se trata de una simple competencia entre pantalla y teatro, en la que este abandona el campo del realismo porque la otra es demasiado eficaz en tal sentido.

Más convincente, la hipótesis del nacimiento de un diálogo, aunque no siempre explícito, entre el nuevo arte y el teatro, una ocasión que se le brindó a este para reflexionar sobre sí mismo como forma estética capaz todavía, pese a los numerosos vaticinios de muerte, de responder, a través del acontecimiento escénico, a los impulsos de una crisis intrínseca y del contexto cultural finisecular, antes, vanguardista, luego. Mediante la contingente confrontación con el cine mudo, por ejemplo, el teatro no eligió el camino más fácil, «un aumento de la valoración de la palabra e incluso un auge excesivo de verborrea con la finalidad de afirmarse en la cualidad más genuina que le alejaba de su competidor» (García-Abad García, 1997a: 503); asumió, en cambio, el desafío que no le venía solo de la pantalla, sino sobre todo de los nuevos presupuestos estéticos que se iban desarrollando en las décadas iniciales del siglo Xx; es más, según García-Abad García (íbidem): «el teatro aprendió del cine una gran lección de mudeza expresiva al poner de manifiesto la gran capacidad del silencio de una imagen ${ }^{4}$.

La idea de un diálogo entre ambas formas no quiere, desde luego, negar el dato histórico, ampliamente documentado en los trabajos de Pérez Bowie (1996, 2004a), García-Abad García (1997a, 1997b), Guarinos (1996), Morales Astola (2003), de los debates y las invectivas mutuas que se intercambiaron intelectuales y creadores durante años; lo que sí afirman la mayoría de los estudiosos en la actualidad es el innegable proceso de reflexión metateatral que supuso la irrupción del nuevo arte, pese al reconocimiento, que tampoco fue tan unánime para con el cine en un principio, de la autonomía de las dos expresiones estéticas. Ya es algo evidente hoy, que el discurso del filme es eminentemente narrativo, lo cual le aproxima, en las técnicas, más al género de la novela que al dramático ${ }^{5}$; sin embargo, algunas coinci-

${ }^{4}$ De la misma autora, acúdase a las páginas de su libro (García-Abad García, 2005), que recoge muchos de sus trabajos sobre el tema. Véase también Pérez Bowie (2004a) y Dougherty (2001).

5 Ya en su libro, Guarinos (1996: 31) lamentaba que «parece que la reflexión teatro-cine desapareció porque la teatralidad no es connatural al cine, mientras que la narratividad, entre otros soportes, pasa de ser potencia a acto en forma de cine». 
dencias de naturaleza pragmática y receptiva, como la forma de fruición colectiva, la implicación del acto de mirar, la presencia de actores y decorados, etc., hicieron que se efrentasen de manera intuitiva el teatro y la pantalla, en una época en que, no hay que olvidarlo, los géneros en prosa seguían midiéndose a través de los conceptos aristotélicos de diégesis y mímesis ${ }^{6}$.

Por cierto, no es una casualidad que una de las claves del debate en torno a las dos artes se refiriera a la cuestión de la mímesis, produciendo una serie de reflexiones, tanto en el bando de los cinéfobos como en el de los cinéfilos, si bien desde posiciones enfrentadas, que hacen patente la necesidad de matizar el concepto de realismo, no siempre percibido negativamente, muy al contrario del execrado naturalismo, del cual el cine, según sus detractores, sería nada menos que una manifestación degenerada. No así lo creían los defensores del nuevo arte, quienes veían en él las posibilidades imaginativas e irrealistas que el teatro tenía que aprovechar de querer emanciparse de la escena naturalista (Pérez Bowie, 2004a: 13-15).

También Morales Astola (2003) aboga por la influencia directa del cine en la renovación de cierta escritura dramática y de la escena, uniéndose a los efectos de una crisis estructural del teatro y de la irrupción de las vanguardias. La lección que aprendería el arte escénico del filme sería la fragmentación del discurso, la idea de montaje y las técnicas de iluminación, todo lo cual, bien mirado, los aleja a ambos del afán de objetivismo de la estética naturalista ${ }^{7}$.

Otro aspecto interesante de las relaciones entre el cine y el teatro es, sin duda, el nexo de los dramaturgos españoles con la industria cinematográfica tanto hollywoodense como española, un tema que ha venido tratando en años recientes y de manera sistemática especialmente Ríos Carratalá (2003), con referencia al período franquista ${ }^{8}$, aunque el interés por tal aspecto se remonta ya a los clásicos y pioneros trabajos de Utrera $(1981,1985)$. La inclusión de este fenómeno en el presente apartado, además de permitir un fá-

${ }^{6}$ Guarinos (1996: 35) subraya que la existencia de una «temprana preocupación por deslindar un arte de otro [...] significa que ambos medios estaban lo bastante implicados como para necesitar esa diferenciación» y, por otra parte, añade Pérez Bowie (2004c: 575), «el afianzamiento del cine como arte específico y dotado de un lenguaje propio no implica, sin embargo, una ruptura total con el arte escénico».

7 Cf. también Pérez Bowie (2004a), Heras (2002) y Cornago Bernal (2001).

${ }^{8}$ El mismo ya se ocupara de las relaciones entre teatro y cine durante el franquismo desde la perspectiva del actor (Ríos Carratalá, 2002). Del período del primer franquismo (1939-1950) también se ha interesado Pérez Bowie (2004b), aunque de manera no circunscrita al fenómeno teatral y con un enfoque diferente, estudiando las relaciones de poder y censura en el campo de las adaptaciones de obras literarias a la pantalla. 
cil enlace con el siguiente, se debe a que, evidentemente, el doble empleo de muchos autores teatrales de posguerra que trabajaron como guionistas supuso algunas influencias en la producción en ambos campos, con impulsos cuyos resultados son frecuentemente, aunque haya excepciones, negativos: «a menudo se intentaba llevar a las pantallas un teatro convencional y pobre en todos los sentidos, aunque funcionara comercialmente de cara al público de la época. El resultado es un cine todavía más pobre, carente de un lenguaje propio y que apenas incluye títulos de calidad» (Ríos Carratalá 2003: 20). De hecho, insiste Ríos Carratalá, la mayoría de estos autores eran los que

dominaban la comedia costumbrista y los distintos géneros del teatro de humor. Eran artesanos capaces de estructurar con oficio y sencillez una historia, conocían las técnicas más elementales del diálogo y, sobre todo, eran conscientes de los gustos de un público que, por aquel entonces, se mostraba más uniforme sin que entre lo teatral y lo cinematográfico se estableciera un deslinde tan significativo como para impedir los trasvases (2003: 19).

\section{LAS APORTACIONES DEL TEATRO AL CINE Y EL CINE DE TEATRO}

La situación que acabo de señalar también atañe, cómo no, al tema de este segundo apartado, pues pone de manifiesto la colaboración que acabó por crearse, a partir de la época de posguerra, entre la gente de teatro y la producción cinematográfica. La atracción de los escritores dramáticos por el nuevo arte, por otra parte, ya se había iniciado durante los años 20 y 30, aunque con mecanismos y resultados muy diferentes. Con cierto grado de aproximación, y remitiendo a las matizaciones presentes en la bibliografía a la que me he venido refiriendo, puede destacarse una actidud de los autores de pre-guerra más centrada en las posibilidades artísticas de la estética fílmica, que abría nuevos caminos para las experimentaciones de los lenguajes expresivos y poéticos, un enfoque que fue impulsado, entre otras cosas, por el clima de las vanguardias y de las nuevas reflexiones en torno a la autonomía del arte; frente a ella, estaría la situación de los escritores de posguerra, más bien vinculada con aspectos de tipo pragmático y, en muchas ocasiones, comercial y/o ideológico.

Otro aspecto de la cuestión concierne a la presencia, en las películas, del teatro, en sus diferentes facetas, como contenido de las obras fílmicas. De ello se ha ocupado especialmente Ríos Carratalá (2000), indicando la escasa 
producción española en este sentido, frente, por ejemplo, a la situación de los países anglosajones. La presencia, si bien pobre, no está exenta de ciertas tipificaciones, lo cual ha dado lugar recientemente a un ensayo de Abuín González (2005), quien intenta trazar una tipología capaz de clasificar las manifestaciones en el llamado filme de teatro. Con este último trabajo dialoga la aportación de Pérez Bowie que se publica en el presente número de Signa, donde el autor propone algunas aclaraciones para la estructuración de una tipología más exhaustiva del fenómeno.

Otra forma de presencia del teatro en la pantalla sería la más estrictamente intertextual, es decir, el uso por parte del cine de los materiales precisamente teatrales: el texto dramático y/o la puesta en escena. Tratándose, empero, de un proceso de transformación y no de una relación extratextual, será conveniente abordarlo en el apartado siguiente, no sin subrayar, para rematar esta sección y la que antecede, la variedad de los fenómenos que atañen a las relaciones entre teatro y cine, en lo que concierne tanto a los aspectos pragmáticos y receptivos como a los rasgos textuales, expresivos y comunicativos, en un diálogo que no deja de surtir sus efectos en la evolución de ambos medios y de la crítica.

\section{LA ADAPTACIÓN, CUESTIÓN ABIERTA}

De entre los muchos argumentos no resueltos en el debate crítico en torno a las relaciones entre teatro y cine, quizás el más problemático siga siendo el fenómeno de lo que comúnmente se ha venido llamando «adaptación», pese a que ni siquiera en la terminología se ha conseguido un acuerdo hasta el momento. Los estados de la cuestión más recientes sobre este aspecto, que yo sepa, están a cargo de Pulido Tirado (2002), Guarinos (2003) y Pérez Bowie (2003 y 2004d) ${ }^{9}$.

Tanto Guarinos como Pérez Bowie ponen de relieve el hecho de que el incremento bibliográfico sobre el tema es muy evidente en el campo de la aplicación práctica y de la explicación de casos concretos, mientras que las aportaciones teóricas siguen siendo escasas. Con todo, los enfoques de varios análisis manifiestan el desplazamiento del interés de los críticos de las meras comparaciones textuales a las consideraciones sobre traducción, transcodificación, reescritura, recreación, trasvase cultural - queriendo utilizar algunos

9 Para una relación de las adaptaciones de textos teatrales en España, léanse Moncho Aguirre (1999 y 2001) y el más reciente de Emilio de Miguel Martínez (2008). 
de los términos propuestos por los investigadores según las tipologías estudiadas - , esto es, interesándose mayormente en los aspectos que conciernen a los lenguajes, los códigos, los discursos teatral y fílmico. «La adaptación teatral», advierte Guarinos (2003: 69), «va indisolublemente unida a la cuestiónacusación de teatralidad fílmica, en tanto que siempre se esperan comentarios de los críticos sobre la supuesta teatralidad de la película en cuestión cuando se conoce el origen dramático de su texto adaptado», pese a que, como la misma estudiosa ha venido defendiendo ya a partir de su trabajo de 1996, el estado de los hechos demuestra que la teatralidad en la película muy a menudo está totalmente desvinculada de la procedencia del sujeto, sino que responde a criterios expresivos propios del proceso de creación fílmica.

Uno de los puntos que más llaman la atención, al tratar de la adaptación, es la indecisión sobre la materia de la misma, puesto que con ella se entiende muy a menudo el uso de textos dramáticos para la pantalla, cuando en principio el hecho teatral supone un proceso de puesta en escena y, a veces, sobre todo en algunas manifestaciones performativas modernas y posmodernas, pero también en otras formas tradicionales de teatro (la Comedia del Arte, por ejemplo) no se contempla la existencia de un texto. La polémica entre texto y representación es materia larga en el campo de la teoría del teatro, sin que en ello intervengan las relaciones de este con el cine, y, sin embargo, dicho sea de paso, el que la cuestión se presente también al abordar la adaptación fílmica, corrobora, si aún fuera necesario, lo acertado de este planteamiento teórico a la hora de investigar lo específico de los códigos y los discursos teatrales.

La consideración de la complejidad del fenómeno, según observa Pérez Bowie (2004d: 278), ha hecho que se evidenciara en años recientes, por parte de los estudiosos, la necesidad de pensar en tipologías menos vinculadas a criterios contenidistas, atendiendo a cuestiones de naturaleza expresiva, discursiva y pragmática, todo lo cual, por ejemplo, impele a Sánchez Noriega (2000) a proponer estudiar el fenómeno como «trasvase cultural» y a Fernández (2000 y 2001) a hablar no tanto de adaptación, sino de «recreación», defendiendo la independencia entre el producto resultante y el de partida $^{10}$. Más, en general, subraya Pérez Bowie (íbidem): «el intento de acuñar una terminología más satisfactoria que sirva para dar cuenta de la variedad de facetas que presenta el fenómeno - traducción, traslación, transposición, etc.—, viene a ser un síntoma de la complejidad del mismo y de la

${ }^{10}$ La influencia más destacada de la reflexión de Fernández viene especialmente de los estudios de Cattrysse (1992), enfocados desde la perspectiva de la teoría de los polisistemas. 
dificultad de atraparlo mediante esquemas reductores». En lo referente a la especificidad de la adaptación de teatro, la clasificación propuesta por Guarinos (1996: 112-113) apunta a la necesidad de observar el fenómeno desde «el punto de vista de la construcción textual y la relación espectatorial de los tres medios [incluyendo la televisión] en tanto espectaculares»y, de hecho, llega a considerar diferencias en el nivel de adaptación, a partir de un grado cero (teatro filmado, vídeos de documentos de puestas en escena, vídeos promocionales), pasando por un grado medio (teatro en televisión, telenovelas y comedias de situación), hasta llegar a un grado pleno (cine teatralizado y cine narrativo). Sánchez Noriega (2000), a partir de las teorías de Helbo (1997), distingue entre la adaptación de textos dramáticos (que puede ser integral o libre) y las que utilizan como materia de partida las representaciones teatrales (grabaciones de representaciones y recreación de una representación en un plató). Trapero (2002) propone una tipología que se base también en los géneros del texto original y del filme.

Muy vinculado con todo lo que precede es otro tópico crítico, el de la fidelidad de la adaptación. Si Ríos Carratalá (2000: 221-222), a partir de un enfoque decididamente pragmático y con un método empírico, basado sobre todo en el comentario de casos específicos, puede afirmar con tranquilidad que «no existen normas rígidas y válidas para definir y estudiar las técnicas de la adaptación» lo hace, a mi manera de ver, sobre todo para cuestionar la trascendencia de esta antigua obsesión, proponiendo, en cambio, algunos criterios de coherencia no sólo intertextual, sino sobre todo intratextual, capaces de «prescindir de los apriorismos». Tiene razón Pulido Tirado (2002: 113) cuando afirma que «más allá del estudio fragmentado, hay que apostar por la construcción de un modelo que, sin que llegue a construir un «contraproducente apriorismo», otorgue una fundamentación teórica clara a esta práctica, posibilidad que Ríos Carratalá no contempla», pero también es verdad que la perspectiva de estudio propuesta por este crítico está más entregada a los aspectos pragmáticos y creativos, como lo demuestra la relación de las once conclusiones que presenta, «como una primera aproximación» (Ríos Carratalá 2000: 221), al final de su libro, en cuyas pautas creo ver una serie de advertencias sobre cómo se hace y se comenta una adaptación cinematográfica de un texto teatral ${ }^{11}$. La idea de fidelidad está siendo debatida, evidentemente, también en el campo más teórico, lo cual es en parte implícito en el hecho que se haya venido cuestionando, como ya apunté más arriba, el con-

${ }^{11}$ La coherencia de este estudioso en mantenerse alejado de una aproximación teórica a tales fenómenos y, por otra parte, apegado a la necesidad de contextualizarlos, resulta evidente también en un reciente articulillo donde vuelve a recorrer la trayectoria de sus estudios (Ríos Carratalá, 2008). 
cepto de adaptación como relación meramente intertextual. Pérez Bowie (2003 y 2004d) resume muy cabalmente las posiciones de los estudiosos en tal sentido, tanto a nivel internacional como en el ámbito español: al fin y al cabo, la mayoría de las tipologías propuestas en los últimos decenios, que intentan clasificar y describir los procesos de adaptación, tienen muy en cuenta la complejidad del fenómeno y, en mayor o menor medida, y de manera más o menos explícita, se niegan a reconocer la validez del criterio de la fidelidad textual basada únicamente en el contenido. Lo mismo pasa, según observo, en muchos de los numerosos artículos y ensayos que se ocupan en analizar y comentar casos específicos de adaptaciones y de los cuales aquí no podré dar cuenta ${ }^{12}$.

Ya Vilches (2001) y Heras (2002) detectaban la existencia de otro fenómeno relativo a la adaptación, esto es, la transformación de películas en espectáculos y, un año más tarde, Guarinos (2003: 63) no dejaba de apuntar que «la situación creadora está dando un vuelco consustancial en los últimos tiempos [...]. Estamos ante la posibilidad más remota y más escasamente producida hasta hoy, la adaptación de una película a obra de teatro, a montaje escénico. Estamos, ya sea por búsqueda de nuevos públicos para el teatro, ya de nuevos lenguajes, ante la relación integral, cubriendo todas las variables posibles, sin fronteras, como sucede con otros medios entre sí». Un estudio reciente a este propósito puede encontrarse en De Miguel Martínez (2008), quien cree que «un elemento común en la totalidad de los casos ha sido la confianza en que el producto teatral resultante va a repetir el éxito ya alcanzado en su andadura cinematográfica. Es decir, el teatro parece estar nu-

${ }^{12}$ Lo que sí, en cambio, me parece oportuno hacer es señalar la existencia de varios volúmenes colectivos, a veces ocasionados por sendos congresos o seminarios consagrados a las relaciones entre teatro y cine, y en los cuales la adaptación de textos específicos suele ser estudiada: Ríos Carratalá y Sanderson (eds.,1999); Vilches (ed., 2001 y 2002); Romera Castillo (ed., 2002); Romera Castillo (ed., 2006); Romera Castillo (ed., 2008). Al estar escribiendo esta introducción, recibo la noticia de que se acaba de publicar un nuevo número de la revista Lecturas: Imágenes, dedicado a este tema (Becerra ed., 2009), pero que desgraciadamente no tendré la oportunidad de consultar y reseñar; dejo aquí constancia, sin embargo, de todos los trabajos que en él se publican: Anxo Abuín González, «Imágenes-cristal: el teatro en el cine»; Laura Borràs Castanyer, «Ciberteatro: posibilidades dramatúrgicas en la era digital»; José Antonio Pérez Bowie, «Hacia un nuevo concepto de la teatralidad cinematográfica. Notas sobre la recepción de las teorías de André Bazin en España (1950-1961)»; Luis Miguel Fernández, «Tecnologías de la visión en el teatro español del siglo XVIII (o cómo ver a través del oído)»; Patricia Fra López, «¿Puede el arte cambiar la sociedad? Cradle Will Rock o un ejemplo de censura política en el teatro y su reflejo en el cine norteamericano»; José Manuel González Herrán, «Hermanas de sangre, una pieza teatral de Cristina Fernández Cubas (1998) filmada para televisión por Jesús Garay (2001)»; Darío Villanueva, «La transformación de la obra literaria: los Macbeth de Roman Polanski y de Harold Bloom». Asimismo, cabe indicar la presencia de una serie de comentarios de adaptaciones en Ríos Carratalá (2000) y unos interesantes análisis en Utrera (2007). 
triéndose de productos cinematográficos por el mismo criterio por el que la pantalla, desde siempre, ha venido alimentándose de historias con éxito ya contrastado en el teatro» (íbid.: 41). Más allá de consideraciones y polémicas posibles acerca de la pertinencia del fenómeno y su carácter más o menos comercial, me permito aquí señalar un aspecto de la cuestión, relevando que a menudo las obras fílmicas que se llevan a la escena son, a su vez, adaptaciones de novelas, lo cual podría dar lugar a observaciones interesantes sobre las relaciones entre los varios medios. Un ejemplo evidente en el ámbito español, es la escenificación en 2007 de Soldados de Salamina, a partir no de la novela de Cercas, sino de la película de David Trueba (2003), pero los casos aumentan si se consideran los filmes extranjeros llevados a las tablas españolas.

Para concluir el presente apartado, me parece oportuno indicar la existencia de algunas aportaciones sobre aspectos específicos de comparación de los dos medios, lenguajes y discursos, que a pesar de no ocuparse en sentido más estricto de la adaptación, sin embargo pueden considerarse como herramientas muy rentables a la hora de teorizar sobre el tema o de analizar obras específicas. Es el caso, entre otros, de Abuín (2001), sobre filmicidad y teatralidad, Cornago Bernal (2001), sobre algunos aspectos estructurales, Heras (2002), sobre los lenguajes y sus contaminaciones, Pérez Bowie (2001, 2005 y 2007), sobre teatro en verso, sobre cine mudo y sobre espacio teatral y espacio cinematográfico, respectivamente.

\section{EL TEATRO EN EL CIRCUITO INTERMEDIAL: NUEVAS TECNOLOGÍAS, ESCENA, COMUNICACIÓN DE MASAS. INTENTOS DE DOMESTICACIÓN Y EVOLUCIONES CREATIVAS Y PERFORMATIVAS}

Guarinos (2003: 68) recuerda, sirviéndose de las palabras de Patrice Pavis (2000), que la intermedialidad es una «integración de conceptos estéticos de los distintos medios de comunicación en un nuevo contexto». De hecho, no se trata de un mecanismo de apropiación por parte de medios más poderosos, ni de un sistema de colonización aniquiladora, sino de un diálogo que no para de volver a poner en juego textos, discursos, códigos, etc. No es este el lugar donde debatir la cuestión de la intermedialidad, pero no cabe duda de que es y va a ser uno de los hitos para el estudio de las relaciones entre el teatro y los medios audiovisuales, produciendo, cómo no, nuevas reflexiones sobre la naturaleza y el funcionamiento de los varios medios implicados. Las 
páginas que anteceden ya pueden leerse como una buena muestra de la rentabilidad del concepto de intermedialidad; con todo, será en el presente apartado donde con más evidencia se aprecie la utilidad de tal enfoque.

Quizá una de las observaciones preliminares para abordar el tema sea la consideración de que el teatro también es una forma de comunicación audiovisual ${ }^{13}$. Esta afirmación, que se apoya, desde luego, en los aspectos pragmáticos y receptivos del arte escénico, manifiesta una de las conquistas de la investigación teórica de las últimas décadas, que ha tardado mucho en independizarse de lo que el italiano De Marinis ha dado en llamar el «imperialismo» de la palabra. Sin llegar a necesitar que el texto dramático desaparezca del marco de los estudios teatrales, baste con apuntar que el mismo, cuando lo haya, va implicado en el contexto escénico, esto es, en una situación de enunciación y de discurso que le aleja de su inicial carácter literario y literal. En los apartados anteriores, el término de comparación e interacción ha sido casi exclusivamente el cine, si se excluye alguna que otra referencia a la televisión; en cambio, en la presente sección ya no tiene mucho sentido distinguir entre formas estéticas demasiado rígidas, sino que es necesario profundizar en el carácter que une a todos los medios que se quieren aproximar: la audiovisualidad.

El enfrentamiento entre el teatro y el cine, ya desde los comienzos de este, quizás responda de manera intuitiva a la existencia de este rasgo común, sobre todo a partir de la irrupción del sonoro, así como los primeros intentos de crear espectáculos híbridos o, en general, de contaminar mutuamente sus lenguajes no parecen estar ajenos a esta percepción de semejanza, si bien intentando deslindar los dos campos ${ }^{14}$. Lo cierto es que existe una historia, en parte todavía por escribir y sistematizar, de las relaciones entre los distintos medios audiovisuales comunicativos y espectaculares, en la que los contactos y las influencias recíprocas entre el cine y el teatro vendrían a ocupar un puesto específico y tendrían una evolución contextualizada, a la par que cualquier otro mecanismo intermedial de naturaleza semejante. Tal historia, sobre todo ahora - que es cuando con más pujanza se está desarrollando a nivel escénico y en la crítica el impulso a la intermedialidad - debería tener en cuenta un aspecto a veces desatendido, esto es, la consideración de que cualquier tecnología, en su momento, es nueva, y produce un impacto en los

13 Las premisas del trabajo de Guarinos (1992: 11-31), para estudiar las relaciones entre el teatro y la televisión, intentan justamente buscar un «lugar común» entre los dos medios.

14 Sobre los espectáculos híbridos y los primeros contactos entre cine y teatro, véanse, entre otros Morales Astola (2003: 89-90); Guarinos (1996: 11-18). 
demás sistemas que comparten con ella unos canales o códigos comunicativos y/o expresivos: tal fue el cine al aparecer, antes de afirmarse también como arte, así como la televisión revolucionó las formas de recepción del espectáculo y la información, y tales son hoy en día, entre otras cosas, las herramientas digitales y las pantallas interactivas.

Por eso, creo, recientemente Pérez Bowie (2006: 5) ha sentido la necesidad de recordar «la estrecha dependencia que siempre han mantenido los espectáculos teatrales con la tecnología disponible en su momento», sobre todo con la tecnología de la imagen. De hecho, los trabajos que se van escribiendo hoy acerca de las relaciones escénicas y creativas entre el teatro y las nuevas tecnologías abordan muy a menudo el tema partiendo del concepto de imagen y de la función de la misma en el marco teatral, tanto en lo referente al espacio, como al cuerpo del actor. Sánchez (2002) propone un repaso de las tendencias escénicas que patentizan la evolución de la consideración del cuerpo para con la imagen a través de los conceptos de presencia/apariencia, natural/artificial, emoción/pensamiento: en los inicios del milenio, afirma él (íbid.: 155), «el cuerpo escénico parece haberse reapropiado de la imagen precisamente para presentarse a sí mismo como algo más que imagen, asumiendo la transformación de los conceptos de naturaleza y naturalidad que los medios audiovisuales y electrónicos han contribuido a producir». Morales Astola (2003: 144-148), por su parte, dedica algunas páginas a describir la situación en la escena española de los 80 y 90 , con referencia a los influjos del cine en el teatro y a las formas de teatro digital, poniendo como ejemplo un experimento de La Fura dels Baus de 1995. Cornago Bernal (2004) insiste, entre otras cosas, en la interacción del cuerpo del actor con la imagen mediatizada ${ }^{15}$. Pérez Royo (2007) se ha interesado por la cuestión de las tecnologías interactivas, estudiando especialmente la evolución escénica en la danza contemporánea hacia una relación de interdependencia mutua entre el espacio y el bailarín. La más reciente contribución al estudio de las relaciones entre el teatro y las nuevas tecnologías es el estado de la cuestión, publicado en el número 17 de Signa, donde pueden encontrarse, entre otros, un ensayo bibliográfico (Romera Castillo, 2008), una reflexión acerca de los estudios sobre recepción y público especialmente en lo referido al teatro digital (López-Varela Azcárate, 2008) y un interesante recorrido por los conceptos clave de la cuestión (Abuín González, 2008), con un apéndice de enlaces a recursos electrónicos

15 También léanse los trabajos publicados en Romera Castillo (ed., 2004) y el artículo de Guarinos (2002). 
de interés. El mismo se había ocupado ya del tema en su libro (Abuín González, 2006), donde también analizaba y clasificaba varias tipologías de manifestaciones escénicas.

Los fenómenos estudiados en los trabajos que acabo de reseñar ponen de manifiesto una evolución en la percepción y recepción del espectáculo y de las relaciones entre presencia física y mediación de la realidad y de la persona humana en la escena; tal evolución ha sido uno de los productos de los procesos de mediatización que, aun no siendo ninguna novedad de última hora, sí han experimentado en los pasados veinte años un rápido incremento tanto en el número de manifestaciones como en la evolución de los medios utilizados al efecto. La cultura de masas, con sus mecanismos de reproducción, repetición, hibridación, etc., ha venido aprovechando las nuevas tecnologías: piénsese en la evolución digital en el desarrollo de la televisión y de los productos de home vídeo o en el alcance de Internet, por no hablar de la portatilidad de la casi totalidad de los medios audiovisuales, todo lo cual no deja de surtir efecto, no sólo en el modo de fruición de los productos, sino también en la creación de los mismos y de continuos mecanismos de estímulo a la intermedialidad y la interactividad, muy a menudo con finalidades comerciales. Con todo, queriendo considerar estos últimos fenómenos como ejemplos de mediatización, algo muy diferente del concepto de intermedialidad como creatividad, conviene concluir este apartado con las palabras de Cornago Bernal (2004: 595):

La relación del teatro con las nuevas tecnologías es un tema que se presta con facilidad a enfoques apocalípticos en torno al futuro del teatro y su siempre cuestionada supervivencia en la sociedad de los medios. Una aproximación distanciada y menos catastrofista nos muestra, sin embargo, que el teatro, como técnica de la representación, ha estado siempre abierto a los adelantos que le han permitido ampliar sus posibilidades de expresión.

\section{BREVE PRESENTACIÓN DE LOS TRABAJOS RECOGIDOS EN ESTE MONOGRÁFICO}

La sección monográfica de este número de Signa recoge unos trabajos en los que se intenta abordar algunas de las cuestiones mencionadas hasta ahora desde distintas perspectivas y a partir de unos enfoques que tienen en cuenta la evolución de los planteamientos críticos y metodológicos de los últimos lustros. 
José Antonio Pérez Bowie ofrece la contribución más teórica, si bien generosamente salpicada de ejemplos concretos, brevemente comentados, capaces de dar cuenta de una posible clasificación tipológica de la teatralidad en la pantalla, siendo éste, en efecto, el tema de su ensayo. El resultado es la sistematización en 10 modos posibles de teatralidad cinematográfica, pudiendo estos repartirse en dos tipos, según se trate de mecanismos que atañen al nivel formal de la película o a su contenido. El trabajo de Marco Cipolloni también puede incluirse dentro de esta problemática, tratando el fenómeno del cineteatro, desde el punto de vista de la presencia del teatro como mundo representado en el cine (y viceversa), interesándose asimismo por las relaciones entre los lenguajes del uno y del otro. La reflexión se enmarca en el amplio contexto hispano y se circuscribe a los momentos históricos de transición de las dictaduras a las democracias.

Las dos contribuciones siguientes pueden incluirse en el tema de la adaptación, aportando las debidas matizaciones a este término, pues analizan dos casos específicos de uso de obras de teatro para la pantalla. María Teresa García-Abad García estudia el ejemplo de Una tal Dulcinea (1961), de Alfonso Paso, llevada al cine en 1963 por Rafael J. Salvia; el análisis es la ocasión para razonar acerca de los mecanismos de la cultura y el imaginario social vinculados con el sustrato mítico. Quien esto escribe ha analizado la reciente producción televisiva de Martes de Carnaval (2008), intentando poner de relieve algunos aspectos de la interacción entre la estética (y la ética) esperpéntica con el medio y las herramientas de la pequeña pantalla.

Finalmente, se proponen dos estudios más, centrados en algunos aspectos de la puesta en escena teatral contemporánea que hace uso de las nuevas tecnologías audiovisuales e interactivas. Milena Locatelli analiza el espectáculo Así que pasen cinco años (2006), montado por los italianos Marco Schiavoni y Caterina Genta, con especial atención a los mecanismos de multimedialidad capaces de vehicular en teatro el surrealismo y la tragedia lorquianas, y que permiten abogar por la representabilidad de la obra. Cierra la sección monográfica el trabajo de Victoria Pérez Royo, quien ofrece un recorrido por las manifestaciones del arte interactivo, desde los años 60 hasta nuestros días, dando cuenta de una evolución hacia lo que en este ensayo se define «giro performativo» de la imagen. 


\section{ENSAYO DE BIBLIOGRAFÍA DE LOS ESTUDIOS SOBRE LAS RELACIONES ENTRE EL TEATRO Y LOS MEDIOS AUDIOVISUALES EN ESPAÑ ${ }^{16}$}

ABUÍN GONZÁLEZ, A. (2001). «Filmicidad y teatralidad: aspectos comparados de la recepción espectacular». En C. Becerra (ed. 2001), Lecturas: Imágenes 1, 24-51.

- (2005). «El filme de teatro: arte frente a industria, o totus mundus agit histrionem». Anthropos 208, 138-151.

- (2006). Escenarios del caos. Entre la hipertextualidad y la performance en la era electrónica. Valencia: Tirant Lo Blanch.

- (2008). «Teatro y nuevas tecnologías: conceptos básicos». Signa. Revista de la Asociación Española de Semiótica 17, 29-56.

BECERRA, C. (ed., 2001). Teatro y cine. Lecturas: Imágenes 6.

CORNAGO BERNAL, Ó. (2001). «Relaciones estructurales entre el cine y el teatro: de la categoría del montaje al acto performativo». En Becerra (ed., 2001), 63-90.

- (2002). «Diálogos a cuatro bandas: teatro, cine, televisión y teatralidad». En Romera Castillo (2002), 549-560.

- (2004). «El cuerpo invisible: teatro y tecnologías de la imagen». Arbor 177 (699-700), 595-610.

DE MIGUEL MARTÍNEZ, E. (2008). «Cine y teatro: pareja consolidada en el arranque del milenio». En Romera Castillo (ed., 2008), 35-56.

DOUGHERTY, D. (2001). «Pensándolo bien: el teatro a la luz del cine (1914-1936)». En Vilches (ed., 2001), 9-26.

ESPÍN, P. (2002). «Pautas teórico-prácticas para el análisis semiótico de obras teatrales en televisión». En Romera Castillo (ed., 2002), 561-569.

FERNÁNDEZ, L. M. (2000). Don Juan en el cine español. Hacia una teoría de la recreación fílmica. Santiago de Compostela: Universidad.

${ }^{16}$ El marco del presente ensayo de bibliografía se limita al período 1992-2009 y a la producción en lengua castellana. Aun mencionando los varios volúmenes colectivos, de éstos tendrán sus referencias específicas sólo los trabajos de tipo histórico, documental, teórico o bibliográfico, quedando excluidas las numerosas aportaciones de muchos estudiosos a nivel más analítico y en lo relativo a casos específicos. Las referencias a los pocos trabajos que exceden estos límites, mencionados en los apartados anteriores, se encuentran al final de esta introducción, en la sección «Otras referencias bibliográficas». 
- (2001). «Una aproximación a la teoría de la recreación fílmica». En C. Becerra (ed. 2001). Lecturas: Imágenes 1, 53-70.

GARCÍA-ABAD GARCÍA, M. ${ }^{\mathrm{a}}$ T. (1997a). «Cine y teatro: dependencias y autonomías en un debate periodístico (1925-1930)». Anales de la Literatura Española Contemporánea 22, 493-509.

- (1997b). «Dos estéticas en contacto: lo cinético y lo dramático». Revista de Literatura 59 (118), 465-481.

- (2005). Intermedios. Estudios sobre literatura, teatro y cine. Madrid: Fundamentos.

GUARINOS, V. (1992). Teatro y televisión, Sevilla: Alfar.

- (1996). Teatro y cine. Sevilla: Padilla.

- (2002). «Lo audiovisual en la puesta en escena teatral». Boletín Galego de Literatura 27, 93-105.

- (2003). «Del teatro al cine y a la televisión: el estado de la cuestión en España». Cuadernos de Eihceroa 2,61-77.

GUTIÉRREZ CARBAJO, F. (2008). «El teatro en el cine español del siglo XXI: narratividad y dramatización». En Romera Castillo (ed., 2008), 57-77.

HERAS, G. (2002). «Mestizajes y contaminaciones del lenguaje cinematográfico con el teatral». En Romera Castillo (ed., 2002), 25-35.

- (2006). «Reflexiones sobre líneas y tendencias de la puesta en escena a comienzos del siglo XXI». En Romera Castillo (ed., 2006), 75-87.

HUESO, Á. L. (2001). «El referente teatral en la evolución histórica del cine». En Vilches (ed., 2001), 45-62.

LÓPEZ MOZO, J. (2002). «Teatro y televisión: ¿un matrimonio bien avenido?». En Romera Castillo (ed., 2002), 157-170.

MAQUEDA CUENCA, E. (2002). «Teatro, adaptación cinematográfica y reescritura». En Romera Castillo (ed., 2002), 399-406.

MONCHO AGUIRRE, J. (1999). «Las adaptaciones teatrales en el cine español». En Peña Ardid (ed., 1999), 225-252.

- (2001). Las adaptaciones de obras del teatro español en el cine y el influjo de éste en los dramaturgos. Alicante: Universidad.

MORALES ASTOLA, R. (2003). La presencia del cine en el teatro (antecedentes europeos y su práctica en el teatro español). Sevilla: Alfar. 
OLIVA, C. (2006). «Experiencias de un espectador experimental. Algunas ideas sobre la modernidad escénica en España en los albores del siglo XXI». En Romera Castillo (ed., 2006), 87-102.

PAZ GAGO, J. M.a (2004). «Ciberteatro: teatro y tecnologías digitales». En Romera Castillo (ed., 2004), 81-88.

- (2006). «La pantalla en escena. Las tendencias tecnológicas en el teatro del siglo XXI». En Romera Castillo (ed., 2006), 151-162.

PEÑA ARDID, C. (ed.) (1999). Encuentros sobre literatura y cine. Zaragoza-Teruel: Instituto de Estudios Turolenses, Caja de Ahorros de la Inmaculada.

PÉREZ BOWIE, J. A. (1996). Materiales para un sueño (En torno a la recepción del cine en España 1896-1936). Salamanca: Librería Cervantes.

- (2001). «Teatro en verso y cine: una relación conflictiva». En Vilches (ed., 2001), 317-335.

- (2003). «La teoría sobre la adaptación cinematográfica de textos literarios. Estado de la cuestión». En Pérez Bowie (ed., 2003).

- (2004a). Realismo teatral y realismo cinematográfico. Las claves de un debate (1910-1936). Madrid: Biblioteca Nueva.

- (2004b). Cine, literatura y poder (1939-1950). Salamanca: Librería Cervantes.

- (2004c). «Teatro y cine: un permanente diálogo intermedial». Arbor 177 (699-700), 573-594.

- (2004d). «La adaptación cinematográfica a la luz de algunas aportaciones teóricas recientes». Signa. Revista de la Asociación Española de Semiótica 13, 277-300.

- (2005). «El teatro en el cine mudo. Análisis de dos ejemplos de la producción española». Anales de la Literatura Española Contemporánea 30 (1-2), 395-432.

- (2006). «Escritura teatral y nuevas tecnologías». Las Puertas del Drama 27, 4-8.

- (2007). «Notas sobre las categorías de espacio teatral y espacio cinematográfico». Las Puertas del Drama 30, 23-27.

- (2008). Leer el cine. Salamanca: Universidad. 
PÉREZ BOWIE, J. A. (ed.) (2003). La adaptación cinematográfica de textos literarios. Teoría y práctica. Salamanca: Plaza Universitaria.

PÉREZ ROYO, V. (2007). «Espacio escénico y tecnologías interactivas». Las Puertas del Drama 30, 11-16.

PULIDO TIRADO, G. (2002). «Los fundamentos teóricos de la relación entre teatro y cine en España. De la adaptación a la transcodificación». En Vilches (ed., 2002), 103-119.

RÍOS CARRATALÁ, A. (2000). El teatro en el cine español. Alicante: Universidad.

- (2002). «Relaciones entre el teatro y el cine en la España del franquismo: la perspectiva del actor». En Vilches (ed., 2002), 121-136.

- (2003). Dramaturgos en el cine español (1939-1975). Alicante: Universidad.

- (2007). «Las mil y una relaciones entre el cine y el teatro». Per Abbat 5, 93-98.

RÍOS CARRATALÁ, A. y SANDERSON, J. D. (eds.) (1996). Relaciones entre el cine y la literatura: un lenguaje común. Alicante: Universidad.

- (eds.) (1999). Relaciones entre el cine y la literatura: el teatro en el cine. Alicante: Universidad.

ROMERA CASTILLO, J. (2008). «Hacia un estado de la cuestión sobre teatro y nuevas tecnologías en España». Signa. Revista de la Asociación Española de Semiótica 17, 17-28.

- (ed.) (2002). Teatro y cine en la segunda mitad del siglo XX. Madrid: Visor Libros.

- (ed.) (2004). Teatro, prensa y nuevas tecnologías. Madrid: Visor Libros.

- (ed.) (2006). Tendencias escénicas al inicio del siglo XXI. Madrid: Visor Libros.

- (ed.) (2008). Teatro, novela y cine en los inicios del siglo XXI. Madrid: Visor Libros.

SALAS, E. A. (2002). «Reflexiones sobre la escenografía en los procesos de recepción teatral y cinematográfica». En Romera Castillo (ed., 2002), 523-532.

SÁNCHEZ, J. Á. (2002). «Cuerpo e imagen en la creación escénica contemporánea». En Vilches (ed. 2002), 137-157. 
SÁNCHEZ NORIEGA, J. L. (1999). «Un modelo teórico-práctico de adaptación cinematográfica de textos teatrales». En Ríos Carratalá y Sanderson (eds., 1999), 59-74.

- (2000). De la literatura al cine. Teoría y análisis de la adaptación. Barcelona: Paidós.

SUÁREZ, A. (2002). «Las producciones televisivas de teatro clásico». En Romera Castillo (ed., 2002), 571-595.

Signa. Revista de la Asociación Española de Semiótica 17 (2008), monográfico dedicado a Teatro y nuevas tecnologías, 1-152.

TRAPERO, P. (2002). «Del teatro al cine: algunas reflexiones acerca del tema». En Romera Castillo (ed., 2002), 47-61.

UTRERA MACÍAS, R. (2007). Literatura y cine. Adaptaciones I. Del teatro al cine. Cuadernos de Eihceroa 7-8.

VILCHES, M. ${ }^{a}$ F. (2001). «La captación de nuevos públicos en la escena contemporánea a través del cine». En Vilches (ed., 2001), 357-382.

VILCHES, M. ${ }^{a}$ F. (ed., 2001). Teatro y cine: la búsqueda de nuevos lenguajes. Vol. 1, Anales de la Literatura Española Contemporánea 26 (1).

- (ed., 2002). Teatro y cine: la búsqueda de nuevos lenguajes. Vol. 2, Anales de la Literatura Española Contemporánea 27 (1).

\section{OTRAS REFERENCIAS BIBLIOGRÁFICAS}

CATTRYSSE, P. (1992). Pour une théorie de l'adaptation filmique. Le film noir américain. Berna: Peter Lang.

GUTIÉRREZ CARBAJO, F. (1993). Literatura y cine. Madrid: Uned.

HELBO, A. (1997). L'adaptation. Du théâtre au cinéma. Paris: Armand Colin.

PAVIS, P. (2000). El análisis de los espectáculos. Teatro, mimo, danza, cine. Barcelona: Paidós.

PEÑA ARDID, C. (1992). Literatura y cine: una aproximación comparativa. Madrid: Cátedra.

URRUTIA, J. (1984). Imago litterae: cine, literatura. Sevilla: Alfar.

UTRERA MACÍAS, R. (1981). Modernismo y 98 frente a cinematógrafo. 
Sevilla: Secretariado de Publicaciones de la Universidad.

- (1985). Escritores y cinema en España: un acercamiento histórico. Madrid: Monteleón.

- (1987). Literatura cinematográfica. Cinematografía literaria. Sevilla: Alfar. 